\title{
GUT MICROBIOTA MODULATION FOR ENHANCED POULTRY PRODUCTION
}

\author{
A. MONDAL ${ }^{1}$, K. DE ${ }^{1}$ AND S. N. JOARDAR ${ }^{2 *}$ \\ ${ }^{1}$ Novus Animal Nutrition (India) Private Limited, Chennai-600 058, Tamil Nadu, India \\ ${ }^{2}$ Department of Veterinary Microbiology, West Bengal University of Animal and Fishery \\ Sciences, Kolkata-700 037, West Bengal, India
}

\begin{abstract}
The poultry gastrointestinal tract (GIT) being rich in diverse microbial community is considered to be effective in optimal nutrient digestion, absorption, immunity development and disease resistance. Gut microbiota varies between poultry flocks due to different factors. The factors may be categorized as extraneous factors like feed, water, environment and host associated factors like breeder's nutrition $\&$ health, hatchery conditions, brooding conditions etc. Modulation of gut microbiota by nutrients and alternative gut health additives gives better impetus to gut protection, host immunity and production performance. Although it has been observed that the association of gut microbiota and productivity of poultry is quite close, specific gut microbial population is yet to be identified that may be exploited to enhance productivity.
\end{abstract}

Key words: Gastrointestinal tract, Gut, Microbiota, Poultry production

\section{Introduction}

As a source of safe and quality protein in human nutrition, poultry meat and egg production are considered precious throughout the world (Shang et al., 2018). By 2050, the world population is expected to touch about 9.6 billion (Borda-Molina et al., 2018). To match the demands of a growing global population, the production of chicken meat and egg are showing exponential growth. Such bumper growth of poultry production is only possible with proper disease prevention strategy. Gut health is the key to optimize nutrient digestion and absorption, immunity development and disease resistance. Several factors viz. the environment, feed and the gastrointestinal microbiota have got impact on the gut integrity and gut health (Shang et al., 2018). Immediately after hatch, the chicken gastrointestinal tract (GIT) being exposed to exogenous microorganism becomes a natural habitat of a wide array of microbiota (Pan and $\mathrm{Yu}, 2014)$. The age of the birds, location in the digestive tract and diet are considered as reasons for the diversity of the chicken gut microbiota (Shang et al., 2018). To understand the impact of gut microbiota on intestinal health and productive performance of the poultry birds an attempt has been made to review the existing literature on the subject and to prepare a scientific compilation based on the surveyed studies.

\section{Chicken gut microbiota and its role}

The chicken GIT contains a complex microbial community (bacteria, fungi, protozoa and viruses) that are dominated by bacteria (Shang 
et al., 2018). An optimal composition of gut microbiota requires for optimal digestion, nutrient absorption, immunity development, better feed conversion and animal performances. The gut microbiota attaches with the epithelial layer of gut forming a protective shield, thereby, reducing the chance for the colonization of pathogenic bacteria (Yegani and Korver, 2008). More than 900 bacterial species are found to inhabit the gut of broiler (BordaMolina et al., 2018). These bacteria produce vitamins, short chain fatty acids, organic acids, antimicrobial compounds and lower triglyceride. Moreover, they induce nonpathogenic immune responses. By this way they provide both nutrition and protection for the animal (Apajalahti, 2005; Yegani and Korver, 2008). It has been noted that, birds that lack gut microbiota are prone to develop disease due to poor immunity (Bailey, 2019). Birds can't digest plant fibers. With the help of gut microbiota this problem can be resolved. It can enhance the growth and production of poultry by producing extra nutrients through the fermentation of the plant fibres (Yadav and Jha, 2019).

\section{Factors influencing modulation of the gut microbiota}

\section{Extraneous factors}

Feed: The dietary components escaping host digestion and absorption serve as the substrate for the growth on intestinal bacteria. This implies that feed has got influence on the growth of gut microbiota in poultry (Pan and $\mathrm{Yu}, 2014$ ). In reality, the balance of gut microbiota is influenced by raw ingredients, nutrient density and the form of the feed. High levels of indigestible, water-soluble non-starch polysaccharides (NSPs) in the feed can increase viscosity in the gut, decreased digesta passage rate, and a decline in nutrient digestibility which in turn favors the growth of $C$. perfringens. This may encourage necrotic enteritis in chicks (Timbermont et al., 2011). The risk of bacterial enteritis can be reduced if we add exogenous NSPase enzyme in feed. The source and level of dietary protein may also affect gut microbiota. Diets with high levels of antinutritional factors in the feed could lead to poor digestibility, resulting in more undigested protein in the intestinal lumen. The presence of undigested protein in the lumen favors the proliferation of pathogenic bacteria, such as C. perfringens (Drew et al., 2004). Supplementing the diet with good quality exogenous protease enzyme has been shown to considerably improve protein digestibility. In addition, dietary fat source has got effect on gut microbiota. This is supported by the report that $C$. perfringens was more abundant in the ileum of broiler chickens fed diet with animal fat than chickens fed diet with soy oil (Knarreborg et al., 2002). It has been observed that high level of calcium in diet for each age group and productive phase may be deleterious to intestinal health. Calcium may chelate nutrients, reduce enzyme activity, and thereby, promoting proliferation of $C$. perfringens (Paiva et al., 2013). Alteration of the normal gut functions such as barrier function and nutrient absorption was observed by the presence of feed contaminated by mycotoxins (Grenier and Applegate, 2013). Adding a broad-spectrum mycotoxin binder to the diet can reduce the adverse effect on mycotoxins on poultry health.

Water: Water quality and water line management are essential for long term gut health benefits and bird's performance. Water quality depends upon water source, water hardness, water $\mathrm{pH}$ and mineral contents in water (Bailey, 2019). Contaminated water with microorganisms is relatively common and has adverse effects on normal functioning of gut health and bird's performances. Water $\mathrm{pH}$ is a key factor that can influence microbial populations in water and in the gut, thus maintaining balance of gut microbiota. The water $\mathrm{pH}$ should be maintained between 5 to 7 because alkaline $\mathrm{pH}$ is shown to 
reduce the activity of digestive enzymes (Oviedo-Randon, 2019). Some studies showed that birds can tolerate a low pH of 3.5 (Abrigo, 2019). Acidic water is unpalatable, while alkaline water obstructs watering systems by depositing excessive mineral, viz. calcium and magnesium. Water outside maximum acceptable levels for both $\mathrm{pH}$ and hardness can create an environment for biofilms and endotoxins to thrive in the water system due to the proliferation of algae and microbes and negatively impacts on bird's performance.

Environment: The local climate in a poultry house is an important factor for poultry performances. The age, phase of production, size of the birds and external environmental conditions, viz. optimum temperature, air velocity and relative humidity are considered vital for poultry health and productivity (Kocaman et al., 2006). The gut microbiota of poultry profiles varies as per the regional and seasonal climatic conditions (Zhou et al., 2016). Feed intake patterns and intestinal motility of poultry may be changed due to different environmental stress factors, viz. heat, cold, humidity and drought. It may cause reduced digestion and poor gut health (Wilson et al., 1980).

\section{Host associated factors}

Breeder's nutrition and health: For proper development of their progeny, optimum nutrition of the breeder birds is necessary (Calini and Sirri, 2007). Egg nutrients obtained from hen are considered to be important for embryonic development. Nutrients viz. vitamin $\mathrm{D}$, trace minerals, carotenoids, and fatty acids have got tremendous effects on gut, and of course, on its immunity development (Calini and Sirri, 2007; Leandro et al., $2011 \mathrm{a}, \mathrm{b}$; Oviedo-Rondón et al., 2013). Breeder hens can transfer good and bad intestinal microbes and immunity to their progeny (Inoue et al., 2008; Leandro et al., 2011a,b). Intestinal commensals and pathogens can be acquired in the pre-hatching phase, directly from the oviduct of the hen (Gantois et al., 2009) or from the environment through the pores in the eggshell. The gut microbiota composition may also be influenced by maternal antibodies. Maternal immunity can provide protection in chicks against enteric pathogens until 14 days of age (Grindstaff et al., 2003; Hamal et al., 2006).

Hatchery conditions: The high hygiene levels of hatcheries influence the development of the GIT and immune system. Some literature reported that increased incubation temperatures reduced enzymatic activity and the relative sizes of the pro-ventriculus, gizzard and intestine (Wineland et al., 2006a,b; Leksrisompong et al., 2007). High incubation temperature induces digestive capacity of the chicks creating more problems of intestine (Smith, 2011). Suboptimal incubation increases hatching window, some chicks to hatch either too early, 36-48 h before pulling chicks out of hatchers, or too late. However, neither of the conditions is suitable for proper development of the gut associated lymphoid tissue (GALT) and general immunity (Shira et al., 2005).

\section{Brooding conditions, farm management and} biosecurity: Brooding management, overall farm management and biosecurity are key factors to maintain gut health and performances (Bailey, 2019). In poultry, production performance, overall health and disease resistance are dependent on the initial development of intestinal microbiota. For proper development of the gut tissues, immune system and microbiota, early access to feed, water and optimal brooding conditions are required. Delayed responses in terms of all immunity parameters are observed in the caeca and colon and on the colonization of lymphocytes in the bursa when the birds are exposed to feed and water after 48 hours of hatching (Shira et al., 2005). This will lead to improper immune activity during the first two 
weeks of life. During this period, most prime vaccines are administered, and chickens are exposed to potential enteric pathogens. Good house ventilation, litter management, proper stock density and lighting programs plays a vital role to maintain the balance of gut microbiota (Dawkins et al., 2004; Olanrewaju et al., 2006; Dunlop et al., 2016; Wang et al., 2016). While providing feed and vaccine, composition of gut microbiota varies. In this situation, provision of sub-optimal management may lead to bacterial enteritis. To have a positive impact on gut health and development of poultry, proper hygienic conditions including bio-security measures are to be followed strictly (Bailey, 2019).

Litter microbiota: Chickens are raised on litter made of pine shavings, rice hulls and other vegetal materials. Many a times, feed, water, and chicken excreta are mixed and composted with the bedding materials. The materials thus produced may sometimes be responsible for changing the contents and characteristics of gut microbiota (Wang et al., 2018). During their growth phase, chicken acquire litter microbes by picking and ingesting liter materials that form a part of its gut microbiota. On the other hand, from faecal matter of birds litter get a unique colony of microbiota with diversified forms (Pan and $\mathrm{Yu}, 2014)$. A close correlation between caecal and litter microbiota was observed with similar type of patterns of microbes is during seasonal variation and environmental conditions in a 1 year long study (Diaz Carrasco, 2019). The load of gut microbiota remaining higher in reused litter and the beds having high moisture content pose a health threat by transmitting pathogens between birds via litter (Oakley et al., 2013).

\section{Microbiota modulation by gut health additives}

Various feed additives, viz. organic acids, essential oils, probiotics, prebiotics, exogenous enzymes and trace minerals can support gut health, immunity and also modulate gut microbiota.

Organic acids: Organic acids are useful in the gut health and production performance of birds. These acids increase the Lactobacillus count in ileum and caecum of birds (Saki et al., 2012). The organic acids lower chyme $\mathrm{pH}$ enhancing pepsin activity, whereas, the peptides obtained from pepsin proteolysis stimulate the release of hormones, viz. gastrin and cholecystokinin. These hormones trigger growth increasing protein digestion (Gauthier, 2002). Dietary supplementation of organic acids disturbs the integrity of bacterial cell membrane and cell macromolecules, thereby interfering nutrient transport and energy metabolism. It causes death of the bacteria in the gut (Ricke, 2003). Addition of organic acids in feed and in water to affect positively on the prevention of enteric diseases and enhanced the immunity, nutrient digestibility and overall production performances of poultry. Water hardness and alkaline water $\mathrm{pH}$ affect crop $\mathrm{pH}$ and consequently reduce the first phase of digestion (Kierończyk et al., 2016). The crop possesses an important role in phytase and other enzyme activity. The enzyme activity is reduced in the tune of $10-15 \%$ when the $\mathrm{pH}$ value of the crop remains above 6.5. The effectiveness is high at pH 4.5-5.5 (Kierończyk et al., 2016). The acidic condition within the crop of broilers is produced by organic acids in feed or water.

Essential oils: The phytogenic feed additives (PFAs) have got varying effects based on their composition. PFAs may act as bacteriostatic or immune-stimulating agents. One category of PFA is a mixture of essential oil compounds (EOC) (Hashemi and Davoodi, 2010). These EOCs viz. carvacrol, thymol and cinnam aldehyde possess selective antimicrobial properties (Lee et al., 2002; Guo et al., 2004). The proliferation of $C$. perfringens can be 
reduced and control of coccidia infection can be made by the use of specific EOC blends (Guo et al., 2004; Mitsch et al., 2004; OviedoRondón et al., 2005, 2010). PFAs have the characteristics in maintaining the intestinal barrier function. It may be seen by increasing in the trans-epithelial electrical resistance of duodenal mucosa of broilers by including thymol in the diet (Placha et al., 2014).

Exogenous enzymes: Being biologically active proteins the exogenous enzymes help in the breakdown of nutrients to smaller compounds hastening further digestion and absorption (Thacker, 2013). Exogenous enzymes including protease, lipase, phytase, and NSPase have been supplemented in diets to improve the digestibility of feed ingredients and modulate the gut microbiota of poultry (Adeola and Cowieson, 2011). Enzymes are the secondbest tool to control the gut microbiota equilibrium. Protease, phytase and NSPase are popular feed supplements for their low-cost and productivity enhancer characteristics (Choct, 2009; Kiarie et al., 2013). Inclusion of exogenous enzymes in diet reduces microbial proliferation by reducing the undigestable nutrients, phytate, digesta viscosity and irritation of gut mucosa that causes inflammation (Kiarie et al., 2013).

Trace minerals: For better intestinal health, the present practice of supplementation of trace mineral to the poultry at higher dose is not advisable (Pierce et al., 2009; Ao T and Pierce, 2013). Chelated form of organic trace mineral possesses different routes of absorption leading to lower interaction with other dietary components. Hence their bioavailability is more in compared to inorganic minerals (Mellor, 1964). The immunity development trace minerals are $\mathrm{Zn}, \mathrm{Mn}, \mathrm{Cu}$, and $\mathrm{Se}$. For modulation of the endogenous mechanisms of defense against infections, inflammations and oxidative stress, trace minerals viz. $\mathrm{Zn}$ and $\mathrm{Cu}$ play crucial role (Mwangi et al., 2017). Zinc is a micro-mineral with important function during the recovery of damage caused by enteric infections (MacDonald, 2000). The poultry industry has used prophylactic concentrations of dietary copper for its ability to improve feed conversion and antimicrobial activity (Bortoluzzi et al., 2020). Manganese being a trace mineral related to better immunity support immunity (Kidd, 2004). Dietary selenium interacts with vitamin $\mathrm{E}$ in antioxidant protection of cells because it's a component of glutathione peroxidase (Kurutas, 2016).

Probiotics: Probiotics may cause modulation of gut micro flora and pathogen inhibition in poultry (Yegani and Krover, 2008; Mondal, 2018). Supplementation of probiotic in poultry diet enhanced nutrient digestibility and improved ileal and caecal microflora composition in the gut (Mountzouris et al., 2010). Probiotics act by multiple mechanisms of action, viz. competitive exclusion of pathogenic bacteria, improved immune response, improve gut barrier function, production of bacteriocins, and improve microbiota homeostasis (Gaggia et al., 2010; Mondal, 2018).

Prebiotics: Prebiotics are popularly known as non-digestible feed ingredients. They are used to manipulate the composition and metabolism of gut microbiota selectively (Piniero et al., 2008). Prebiotics enhances the growth of Bifidobacteria and other species thereby improving the gut health (Scott et al., 2020). These can be a potential feed additive to modulate microbiota for better growth and improved poultry health.

\section{Microbiota composition vs. productive performance}

Albeit the feed conversion ratio (FCR), calculated as the ratio of feed consumed to weight gained, is the most frequently used parameter; different other 
traits, viz. residual feed intake (RFI), body weight gain (BWG), apparent metabolized energy (AME), time to achieve market weight are also used to assess the growth performance (Stanley et al., 2013). The factors that influence the microbiota composition modulate the productivity and variability in performance in birds.

It has been observed that some bacteria are directly connected to productive performance of poultry. They are Lactobacillus salivarius, Lactobacillus aviarius, Lactobacillus crispatus, Clostridium lactatifermentans, besides members of family Ruminococcaceae, Bacteroides vulgatus, Akkermansia and Faecalibacterium (Yan et al., 2017). The high prevalence of coliforms in gut leads to lower fat digestibility and consequently lower growth of broiler. On the other hand, colonization of Campylobacter in the gut of broiler was observed to enhance cumulative FCR leading to economic loss 2015; (Awad et al., 2015; Rubio et al., 2015).

The restrictive feeding strategy was considered to be an option to reveal the effect of feed intake upon microbial colonization in ileum and cecum vis-à-vis physiological activities of poultry. It was done with different residual feed intake (RFI) as measure of feed efficiency. It was observed that the predominant families, viz. Turicibacteraceae, Ruminococcaceae, and Enterobacteriaceae were affected by restrictive feeding more in both sections of gut regardless of RFI (Siegerstetter et al., 2018). Further, few taxa were found to be connective with productivity level compared with the impact of nutrient availability on the microbiota richness.

It was observed that Acinetobacter, Anaerosporobacter, and Arcobacter were abundant in faecal matter in birds having the lower feed efficiency group whereas members of Enterobacteriaceae and Faecalibacterium were found to be prevalent in the better feed efficiency group. However, the relative abundance of some bacteria in feces should not be corroborated with the prevalence of similar microbiota in poultry GIT (Yan et al., 2017; Siegerstetter et al., 2018). Therefore, one should be cautious in interpreting results while comparing or evaluating productive performance of poultry birds (Diaz Carrasco et al., 2019).

In short, the association of gut microbiota and productivity of poultry has been studied widely and found to be quite close. However, the findings are not always anticipated. Most of the time, identification of specific bacteria related to the productive performances and establishing cause/effect relationship is difficult.

\section{Conclusion}

Gut microbiota is an important component of gastrointestinal ecosystem. Modulation of composition and function of the gut microbiota by improving feed and water quality, environmental conditions, farm management, biosecurity, hatchery conditions, breeder health and nutrition and use of various gut health additives like organic and essential oils, trace minerals, probiotics and prebiotics can play vital role for successful poultry production. Modulations of gut microbiota by implementing dietary and managerial strategies have been used by poultry producers to enhance bird's performance and reduce the incidence of diseases. Nonetheless gut microbiota and productive performance of poultry has got close relationship, more studies are needed to identify specific gut microbial population that can be exploited to enhance productivity.

Conflict of interest: Authors declare that they have no conflict of interest.

\section{ACKNOWLEDGEMENTS}

Authors thank the Managing Director, South Central Asia, Novus International and the Hon'ble Vice Chancellor, WBUAFS, Kolkata (W.B.) for their infrastructural support. 


\section{REFERENCES}

Abrigo D, 2019. Water: the critical nutrient for ABF production. Asian Poult Magazine, October issue: $10-11$

Adeola $\mathrm{O}$ and Cowieson AJ, 2011. Opportunities and challenges in using exogenous enzymes to improve nonruminant animal production. J Anim Sci, 89(10): 3189-3218, doi: 10.2527/ jas.2010-3715

Apajalahti J, 2005. Comparative gut microflora, metabolic challenges, and potential opportunities. J Appl Poult Res, 14: 444-453, doi: 10.1093/japr/14.2.444

Ao T and Pierce J, 2013. The replacement of inorganic mineral salts with mineral proteinates in poultry diets. Worlds P Sci J, 69:5-16, doi: 10.1017/ S0043933913000019

Awad WA, Smorodchenko A, Hess C, Aschenbach JR, Molnár A et al., 2015. Increased intracellular calcium level and impaired nutrient absorption are important pathogenicity traits in the chicken intestinal epithelium during Campylobacter jejuni colonization. Appl Microbiol Biotechnol, 99: 6431-644, doi: 10.1007/s00253-015-6543-Z

Bailey R, 2019. Key factors in the development of optimal gut function. Int Hatch Prac, 33 (6): 25-27

Borda-Molina D, Seifert J and Camarinha-Silva A, 2018. Current perspectives of the chicken gastrointestinal tract and its microbiome. Comput Struct Biotechnol J, 16: 131-139, doi: 10.1016/ j.csbj.2018.03.002

Bortoluzzi C, Vieira BS and Applegate TJ, 2020. Influence of dietary zinc, copper,and manganese on the intestinal health of broilers under Eimeria challenge. Front Vet Sci, 7: 13, doi: 10.3389/ fvets. 2020.00013

Calini F and Sirri F, 2007. Breeder nutrition and offspring performance. Braz J Poult Sci, 9:77-83, doi: 10.1590/S1516-635X2007000200001

Choct M, 2009. Managing gut health through nutrition. Br Poult Sci, 50: 9-15, doi: 10.1080/ 00071660802538632

Dawkins MS, Donnelly CA and Jones TA, 2004. Chicken welfare is influenced more by housing conditions than by stocking density. Nature, 427 : 342-344, doi: 10.1038 /nature02226

Diaz Carrasco JM, 2019. Seasonality as a driver of cecal and litter microbiota variation in commercial broiler chickens. In Proceedings of the Symposium on Gut Health in Production of Food Animals, St Louis, MI, USA, 4-6 November 2019; pp13

Diaz Carrasco JM, Casanova NA and Fernandez Miyakawa ME, 2019. Microbiota, gut health and chicken productivity: what is the connection? Microorganisms, 7: 384, doi: 10.3390/ microorganisms 7100374

Dunlop MW, Moss AF, Groves PJ, Wilkinson SJ, Stuetz RM et al., 2016. The multidimensional causal factors of wet litter in chicken meat production. Sci Total Environ, 562: 766-776, doi: 10.1016/ j.scitotenv.2016.03.147

Drew MD, Syed NA, Goldade BG, Laarveld B and Van Kessel AG, 2004. Effects of dietary protein source and level on intestinal populations of Clostridium perfringens in broiler chickens. Poult Sci, 83: 414-420, doi: 10.1093/ps/83.3.414

Hashemi SR and Davoodi H, 2010. Phytogenics as new class of feed additive in poultry industry. J Anim Vet Adv, 9(17): 2295-2304, doi: 10.3923/ java.2010.2295.2304

Gaggia F, Mattarelli P and Biavati B, 2010. Probiotics and prebiotics in animal feeding for safe food production. Int J Food Microbiol, 141(Suppl 1): S15-28, doi:10.1016/j.ijfoodmicro.2010.02.031

Gantois I, Ducatelle R, Pasmans F, Haesebrouck F, Gast R et al., 2009. Mechanisms of egg contamination by Salmonella enteritidis. FEMS Microbiol Rev, 33: 718-738, doi: 10.1111/ j.1574-6976.2008.00161.x

Gauthier R, 2002. Intestinal health, the key to productivity: The case of organic acids. IASA XXVII convencion ANECA-WPDC. Puerto Vallarta, Mexico

Grindstaff JL, Brodie EDIII and Ketterson ED, 2003. Immune function across generations: integrating mechanism and evolutionary processin maternal antibody transmission. Proc Biol Sci, 270: 23092319, doi: 10.1098/rspb.2003.2485 
Grenier B and Applegate T, 2013. Modulation of intestinal functions following mycotoxin ingestion: meta-analysis of published experiments in animals. Toxins, 5: 396-430, doi: 10.3390/ toxins5020396

Guo FC, Williams BA, Kwakkel RP, Li HS, Li XP et al., 2004. Effects of mushroom and herb polysaccharides, as alternatives for an antibiotic, on the cecal microbial ecosystem in broiler chickens. Poult Sci, 83: 175-182, doi: 10.1093/ ps/83.2.175

Hamal KR, Burgess SC, Pevzner IY and Erf GF, 2006. Maternal antibody transfer from dams to their egg yolks, egg whites, and chicks in meat lines of chickens, Poul Sci, 85: 1364-1372, doi: 10.1093/ ps/85.8.1364

Inoue AY, Berchieri Jr A, Bernardino A, Paiva JB and Sterzo EV, 2008. Passive immunity of progeny from broiler breeders vaccinated with oil-emulsion bacterin against Salmonella enteritidis. Avian Dis, 52: 567-571, doi: 10.1637/8096-082707-Reg.1

Kiarie E, Romero LF and Nyachoti CM, 2013. The role of added feed enzymes in promoting gut health in swine and poultry. Nutr Res Rev, 26: 71-88, doi: 10.1017/S095442 2413000048

Kidd MT, 2004. Nutritional modulation of immune function in broilers. Poult Sci, 83(4): 650-657, doi: $10.1093 / \mathrm{ps} / 83.4 .650$

Kierończyk B, Rawski M, Długosz J, Swątkiewicz S and Józefiak D, 2016. Avian crop function - A review. Ann Anim Sci, 16: 653-678, doi: 10.1515/ aoas-2016-0032

Knarreborg A, Simon MA, Engberg RM, Jensen BB and Tannock GW, 2002. Effects of dietary fat source and subtherapeutic levels of antibiotic on the bacterial community in the ileum of broiler chickens at various ages. Appl Environ Microbiol, 68: 5918-5924, doi: 10.1128/AEM.68.12.59185924.2002

Kocaman B, Esenbuga N, Yildiz A, Laçin E and Muhlis M, 2006. Effect of environmental conditions in poultry houses on the performance of laying hens. Int J Poult Sci, 5: 26-30

Kurutas EB, 2016. The importance of antioxidants which play the role in cellular response against oxidative/nitrosative stress: current state. Nutr J, 15: 71, doi: 10.1186/s12937-016-0186-5

Lee KW, Everts H, Beynen AC, Williams P and Losa $\mathrm{R}, 2002$. Essential blending of essential oils in broiler nutrition. Int J Poult Sci, 3: 738-752

Leandro NM, Ali R, Koci M, Moraes V, Malheiros RD et al., 2011a. Effects of broiler breeder genetic, diet type, and feeding program on maternal antibody transfer and development of lymphoid tissues of chicken progeny. J Appl Poult Res, 20: 474-484, doi: 10.3382/japr.2010-00268

Leandro NM, Ali R, Koci M, Moraes V, EusebioBalcazar PE et al., 2011b. Maternal antibody transfer to broiler progeny varies among strains and is affected by grain source and cage-density. Poult Sci, 90: 2730-2739, doi: 10.3382/ps.201101573

Leksrisompong N, Romero-Sanchez H, Plumstead KE and Brake J, 2007. Broiler incubation.1. Effect of elevated temperature during late incubation on body weight and organs of chicks. Poult Sci, 86: 2685-2691, doi: 10.3382/ps.2007-00170

MacDonald RS, 2000. The role of zinc in growth and cell proliferation. J Nutr, 130: 1500S-1508S

Mellor DP, 1964. Historical Background and Fundamental Concepts of Chelation. In: Dwyer FP, Mellor DP. editors. Chelating Agents and Metal Chelates. New York, NY: Academic Press, pp1, doi: 10.1016/B978-0-12-395499-2.50007-4

Mitsch P, Zitterl-EglseerK, Köhler B, Gabler C, Losa R et al., 2004. The effect of two different blends of essential oil components on the proliferation of Clostridium perfringens in the intestines of broiler chickens. Poult Sci, 83: 669-675, doi: 10.1093/ps/83.4.669

Mondal A, 2018. Bacillus group probiotics- An ideal choice for poultry production. Poultry Line, 18(12): 59-61

Mountzouris KC, Tsitrsikos P, Palamidi I, Arvaniti A, Mohnl M et al., 2010. Effects of probiotic inclusion levels in broiler nutrition on growth performance, nutrient digestibility, plasma immunoglobulins, and cecal microflora composition. Poult Sci. 89 (1): 58-67, doi: 10.3382/ps.2009-00308 
Mwangi S, Timmons J, Ao T, Paul M, Macalintal L et al., 2017. Effect of zinc imprinting and replacing inorganic zinc with organic zinc on early performance of broiler chicks. Poult Sci, 96: 861-868, doi: 10.3382/ps/pew312

Oakley BB, Morales CA, Line J, Berrang ME, Meinersmann RJ et al., 2013. The poultryassociated microbiome: network analysis and farm-to-fork characterizations. PLoS One, 8, e57190, doi: 10.1371/journal.pone.0057190

Olanrewaju HA, Thaxton JP, Dozier III WA, Purswell J, Roush WB et al., 2006. A review of lighting programs for broiler production. Int J Poult Sci, 5(4): 301-308

Oviedo-Rondón EO, Clemente-Hernandez S, Williams $\mathrm{P}$ and Losa R, 2005. Responses of broilers vaccinated against coccidia to essential oil blends supplementation: live performance in a production period. J Appl Poult Res, 14: 657-664

Oviedo-Rondón EO, Hume ME, Barbosa NA, Sakomura NK, Weber G et al., 2010. Ileal and cecal microbial populations in broilers given specific essential oil blends and probiotics in two consecutive grow-outs. Avian Res, 3: 157-169, doi: 10.3184/ 175815511X12919853724050

Oviedo-Randon EO, 2019. Holistic view of intestinal health in poultry. Anim Feed Sci Tech, 250: 1-8, doi: 10.1016/j.anifeedsci.2019.01.009

Pan D and Yu Z, 2014. Intestinal microbiome of poultry and its interaction with host and diet. Gut Microbes, 5(1): 108-119, doi: 10.4161/gmic. 26945

Paiva D, Walk CL and Mcelroy AP, 2013. Influence of dietary calcium level, calcium source, and phytase on bird performance and mineral digestibility during a natural necrotic enteritis episode. Poult Sci, 92(12): 3125-3133, doi: 10.3382/ps.201303298

Pierce J, Ao T, Charlton $\mathrm{P}$ and Tucker LA, 2009. Organic minerals for broilers and laying hens: reviewing the status of research so far. Worlds P Sci J, 65: 493-498, doi: 10.1017/ S004393390900035X

Piniero M, Asp NG and Reid G, 2008. FAO technical meeting on prebiotics. J Clin Gastroenterol,
42(Suppl. 3, Part 3): S156-S162, doi: 10.1097/ MCG.0b013e31817f184e

Placha I, Takacova J, Ryzner M, Cobanova K, Laukova A et al., 2014. Effect of thyme essential oil and selenium on intestine integrity and antioxidant status of broilers. British Poult Sci, 55: 105-114, doi: $10.1080 / 00071668.2013 .873772$

Ricke SC, 2003. Perspectives on the use of organic acids and short chain fatty acids as antimicrobials. Poult Sci, 82(4): 632-639, doi: 10.1093/ps/82.4.632

Rubio LA, Peinado MJ, Ruiz R, Suárez-Pereira E, Ortiz Mellet C et al., 2015. Correlations between changes in intestinal microbiota composition and performance parameters in broiler chickens. J Anim Physiol Anim Nutr, 99: 418-423, doi: 10.1111/jpn.12256

Saki AA, Harcini RN, Rahmatnejad E and Salary J, 2012. Herbal additives and organic acids as antibiotic alternatives in broiler chicken's diet for organic production. Afr J Biotechnol, 11(8): 2139-2145, doi: 10.5897/AJB11.797

Scott KP, Grimaldi R, Cunningham M, Sarbini SR, Wijeyesekera A et al., 2020. Developments in understanding and applying prebiotics in research and practice-an ISAPP conference paper. J Appl Microbiol, 128: 934-949, doi: 10.1111/ jam. 14424

Smith JA, 2011. Experiences with drug-free broiler production. Poult Sci, 90: 2670-2678, doi: 10.3382/ps.2010-01032

Shang Y, Kumar S, Oakley B and Kim WK, 2018. Chicken gut microbiota: importance and detection technology. Front Vet Sci, 5: 1-11, doi: 10.3389/fvets.2018.00254

Shira EB, Sklan D and Friedman A, 2005. Impaired immune responses in broiler hatchling hindgut following delayed access to feed. Vet Immunol Immunopatholol, 105: 33-45, doi: 10.1016/ j.vetimm.2004.12.011

Siegerstetter SC, Petri RM, Magowan E, Lawlor PG, Zebeli Q et al., 2018. Feed restriction modulates the fecal microbiota composition, nutrient retention, and feed effiency in chickens divergent in residual feed intake. Front Microbiol, 9: 2698, doi: $10.3389 /$ fmicb.2018.02698 
Stanley D, Geier MS, Denman SE, Haring VR, Crowley TM et al., 2013. Identification of chicken intestinal microbiota correlated with the efficiency of energy extraction from feed. Vet Microbiol, 164: 85-92, doi: 10.1016/j.vetmic.2013.01.030

Thacker PA, 2013. Alternatives to antibiotics as growth promoters for use in swine production: A review. J Anim Sci Biotechnol, 4: 35, doi: 10.1186/20491891-4-35

Timbermont L, Haesebrouck F, Ducatelle R and Van Immerseel F, 2011. Necrotic enteritis in broilers: An updated review on the pathogenesis. Avian Pathol, 40: 341-347, doi: 10.1080/ 03079457.2011 .590967

Wang L, Lilburn M and Zhongtang Y, 2016. Intestinal microbiota of broiler chickens as affected by litter management regimens. Front Microbiol, 7: 593, doi: 10. 3389/fmicb.2016.00593

Wang S, Chen L, He M, Shen J, Li G et al., 2018. Different rearing conditions alter gut microbiota composition and host physiology in Shaoxing ducks. Sci Rep, 8: 7387, doi: 10.1038/s41598018-25760-7

Wilson EK, Pierson FW, Hester PY, Adams RL and Stadelman WJ, 1980. The effects of high environmental temperature on feed passage time and performance traits of white Pekin ducks. Poult Sci, 59: 2322-2330, doi: 10.3382/ps.0592322

Wineland MJ, Christensen VL, Yildirim I, Fairchild
BD, Mann KM et al., 2006a. Incubator temperature and oxygen concentration at the plateau stage in oxygen consumption affects intestinal maturation of broiler chicks. Int J Poult Sci, 5: 229-240

Wineland MJ, Christensen VL, Yildirum I, Fairchild BD, Ort DT et al., 2006b. Incubator environment interacts with the genetic line of broiler at the plateau stage to affect embryo plasma thyroxine and triiodotyrosine concentrations. Int J Poult Sci, 5: $714-722$

Yadav S and Jha R, 2019. Strategies to modulate the intestinal microbiota and their effects on nutrient utilization, performance, and health of poultry. J Anim Sci Biotechnol, 10: 2, doi: 10.1186/s40104018-0310-9

Yan W, Sun C, Yuan J and Yang N, 2017. Gut metagenomic analysis reveals prominent roles of Lactobacillus and cecal microbiota in chicken feed efficiency. Sci Rep, 7: 45308, doi: 10.1038/ srep45308

Yegani M and Korver DR, 2008. Factors affecting intestinal health in poultry. Poult Sci, 87: 20522063, doi: 10.3382/ps.2008-00091

Zhou X, Jiang X, Yang C, Ma B, Lei C et al., 2016. Cecal microbiota of Tibetan Chickens from five geographic regions were determined by $16 \mathrm{~S}$ rRNA sequencing. Microbiol open, 5: 753-762, doi: $10.1002 / \mathrm{mbo} 3.367$ 